\title{
Knowledge and Practice Regarding Breastfeeding among Primipara Mothers of Obstetrics Ward, Birganj, Nepal
}

\author{
Yumkhaibam Renubala Devi ${ }^{1}$, Rajwant Kaur Randhawa ${ }^{2}$, Priyanka Chaudhary ${ }^{3}$ \\ ${ }^{1} \mathrm{Ph} . \mathrm{D}$ Scholar, Desh Bhagat University, Punjab \\ ${ }^{2}$ Professor, DBU, Punjab \\ ${ }^{3}$ Associate Professor, DBU, Punjab \\ Corresponding Author: Yumkhaibam Renubala Devi
}

DOI: https://doi.org/10.52403/ijhsr.20220108

\begin{abstract}
Breastfeeding is an ideal form of feeding to neonate. It is most precious gift a mother can give and is free of cost. It should be started as soon as possible after birth. Breast milk is a species-specific complete food. Human milk facilitates effortless digestion for infant and is well absorbed by the newborn. It helps in stimulating the production of breast milk, protect against infection and facilitate mother infant bonding and promotes better brain growth. For mothers breastfeeding helps in involution of uterus, delays pregnancy and lower risk of breast and ovarian cancer. Every year around 57,000 children below 5 years of age lose their lives, among which 54 percent die within the first month of life. The data stated that 22 percent of newborn death can be prevented through breastfeeding within $1^{\text {st }}$ hour of birth. Mother play a very important roles in reducing neonatal mortality and neonatal morbidity rate by their knowledge and practice while feeding their baby.

Method: Descriptive correlation study design was conducted in the month of August 2021 National Medical College and Teaching Hospital, Birganj, Nepal. Sample size was 50 primi para mothers. Purposive sampling techniques was used to select the sample. Semi structure interview schedule and observation checklist was prepared according to objectives which comprised questions related to demographic variables, Knowledge to assess breastfeeding and observational checklist to assess practice Data was collected by administering this structured questionnaire to the primipara mothers.

Result: In the study 31 (62.0\%) had adequate, 19 (38.0\%) had moderate and none of them had inadequate knowledge regarding breastfeeding. 23 (46.0 had good, 27 (54.0\%) had satisfactory and none of them had poor practice on breastfeeding. The results show that there was moderate degree positive correlation between knowledge and practice.
\end{abstract}

Keywords: Knowledge, practice, breastfeeding and primipara mothers.

\section{INTRODUCTION}

Breastfeeding is the most ideal form of feeding to neonate and infant to satisfy nutritional, metabolic and psychological needs of the baby. Breastfeeding should be initiate as soon as possible after birth. The first milk or colostrum is most suitable for babies as it contains high concentration of nutrients. Human milk facilitates effortless digestion for infants and is well absorbed by the newborn. It is readily available and always at the right temperature, requires no mixing sterilization or equipment and is safe regardless of quality and availability of water. Its composition changes feeding to feeding and even within feeding. Exclusive breastfeeding must be ensured to mothers during the first 6 months of life. Breast milk is unique food adapted to nutritional needs of offspring in mammals and is one that 
saves life of human beings. It contains all nutrients vital for nourishments as well as growth factors believed to help in tissue development and antibodies to fend infections. Breastfeeding is the nature's way of nurturing the baby creating a strong bond between mother and the child which promotes better brain growth. It provides development and learning opportunities to the infant, stimulating all five senses of the child sight, smell, hearing taste and touch. Breastfeeding fosters emotional security and affection with a lifelong impact on psychological development. Special fatty acids in breast milk led to increased intelligence quotients (IQ) and better visual acuity. Breastfed are likely to have an IQ of around 8 points higher than on breastfed baby. For mothers breastfeeding helps in involution of uterus, delays pregnancy and lower risk of breast and ovarian cancer.

Only $45 \%$ babies are breastfeed within the first hour of birth and 85\% babies are breastfeed within a day. Approximately 700,000 children are born everyday in Nepal. Around 25\% of babies are nourished with pretacteal feed. Also $70 \%$ babies are breastfeed from birth to 6 month and 88\% from birth to one month. Currently, only $74 \%$ babies in Nepal are breastfeed exclusively between 0 -3months of age and 53\% between 4-5 month are never breastfeed according to survey (NDHS, 2011) breastfeeding has been accepted as the most vital intervention for reducing infant mortality and ensuring optimal growth and development of children (International Baby Food Action Network [IBFAN], 2007) Research conducted worldwide indicates that babies who are not on breastfeed are 25 times more susceptible to disease (2014)

\section{MATERIALS AND METHODS}

A descriptive correlation study was conducted among 50 primipara mothers admitted in Obstetric ward of NMCTH, Birganj, Nepal. The objective of the study was to identify knowledge and practice regarding breastfeeding among primi postnatal mothers. Postnatal mothers with breastfeeding infants between 0-1 month either normal vaginal delivery or caesarean section were included in the study and those mothers whose babies were very sick need for emergency care were excluded from the study. An informed consent was obtained from the respondents who were willing to participate. Semi-structure interview schedule and an observational checklist was developed to collect the data on the sociodemographic variables, knowledge and practice regarding breastfeeding among primipara mothers. It was comprised three sections -

Section I: Consist of 10 question items related to socio- demographic variables.

Section II: Consist of 30 question items with four options which include one correct answer.

Section III: Observational checklist consist of two options Yes/ No, to assess practice regarding breastfeeding.

The tool was validated by seven subject experts. The reliability of the structured questionnaire was obtained by using split half method which was found to be 0.8 and the reliability of the observational checklist was obtained by using interrater reliability test which was found to be 0.87 . The data was collected in the month of August 2021.

\section{STATISTICAL ANALYSIS:}

The collected data were tabulated, analyzed and interpreted through frequencies, percentages and standard deviation. Excel and SPSS (Statistical Package for Social Science) were used for analysis of data.

\section{RESULTS}

This study was conducted among 50 primipara postnatal mothers. Majority of the women 25 (50\%) were from age group 1520 years,38 (76\%) was hindu,41 (82\%) was from rural area, 41 (82\%) had undergone vaginal delivery with episiotomy, 27 (54\%) were illiterate, 19 (38\%) were belongs to joint family, 42 (84\%) were housewife, 27 
(54\%) had Rs.10,000 - 20,000 monthly income and 45 (90\%) have received information regarding breastfeeding from family members and friends. 31(62\%) of women had adequate knowledge, 19 (38\%) had moderate and none of the respondents had inadequate knowledge on breastfeeding. 23 (46\%) had good practice, 27 (54\%) had satisfactory practice and none of respondents had poor practice.

The correlation between knowledge and practice score regarding breastfeeding ' $r$ ' was 0.562 which indicated that the knowledge level of the mothers and their practice were positively correlated to each other.

\section{DISCUSSION}

This study reveals that out of 50 mothers, 31 (62\%) of women had adequate knowledge, 19 (38\%) had moderate knowledge on breastfeeding. 23 (46\%) had good practice and 27 (54\%) had satisfactory practice on breastfeeding.

According to a study conducted in Government hospital of Dharapuram among 30 primipara mothers to assess the knowledge and practice regarding breastfeeding reveals that $86.67 \%$ of mothers had adequate knowledge and $13.33 \%$ had moderate Knowledge. 66.67\% had satisfactory practice and $33.33 \%$ had moderately satisfactory practice regarding breastfeeding. This study reveals that the knowledge level of the mothers and their practice are positively correlated to each other as $r$ value is 0.562 which is significant at 0.01 level which implies that when there is increase in knowledge, practice will also be increase. Comparative study could be conducted between primipara and multipara mothers with larger sample size in different setting.

\section{CONCLUSION}

Mothers play a very important roles for the normal growth and development of a child which require a good knowledge and practices on breastfeeding their baby. Breastfeeding not only support for the normal growth and development but also fosters emotional security and affection, with a lifelong impact on psychological development.

The overall result of the study shows that when there is increase in knowledge, practice will also be increase. The major strength of the study is that the study has covered a significant issue related to mothers and child health but the study was limited to only 50 samples in obstetric ward of NMCTH.

\section{Acknowledgement: None}

\section{Conflict of Interest: None}

\section{Source of Funding: None}

\section{REFERENCES}

1. Bansal, CP. Breastfeeding. Why are we still failing? Indian Pediatric Journal (2013); 50: 993-994. Available on: www.indianpediatrics.net/nov2013/nov993-994.htm.

2. Banstola, A. World Breastfeeding Week and the Challenges in Nepal. Public Health Prospective Nepal (2013): 3(8).425-30 Available on: http://phpnepal.org/indeBx.php?listid=490\#. VMM600eUdpg

3. Bhattarai, H.K. Neonatal mortality in Nepal: A Public Health Concern. Health Prospect. (2011) ;10: 37-38. Available on: http://www.healthprospect.org/archives/arch ive 2011/37-38.pdf.

4. Chaudhary, J., Dhungana, G.P.\&Ghimire, H.C. Factors affecting new born care practices among tharu mothers in selected village development committee of Chitwan District. Journal of Chitwan Medical College 3(2013); (3): 42-45. Available on: http://www.nepjol.info/index.php/JCMC/art icle/view/8465

5. Chapagain, R.H. Knowledge and practices of mothers of infant and young child on complementary feeding. Kathmandu; (2014): 201-8 Available on: http://www.researchgate.net/publication/232 237398 Knowledge and practice of mothers of infant and young child on complementary feeding. 
6. Chaudhary, RN. Shah, T. \& Raja, S. (2011). Knowledge and practice of mothers regarding breastfeeding: A Hospital Based Study. Health Renaissance, 9 (3): 194-200. Available on: http://www.nepjol.info/index.php/HREN/art icle/viewFile/5590/4605.

7. Dutta, A. (2014). Infant feeding practices and the underlying factors among primipara mothers. Indian Journal of Nursing Studies, 5 (1): 54-61. Available on: http://www.cconursing.com/Collegejournal. pdf.

8. Ekambaram, M., Bhat, VB. and Mohamed Ahamed, AF. (2010). Knowledge, attitude and practice of breastfeeding among postnatal mothers. Jawaharlal Institute of postgraduate Medical Education and Research, Puducherry, India, 14(2): 119124. Available http://indmedica.com/journals.php?journalid $=13 \&$ issueid $=145 \&$ articleid $=1955 \&$ action $=$ article

9. Kumari, S., Saili, A., Jain, S., Bhargava, U., Gandhi, G. \& Seth, P. (1988). Maternal attitude and practices in initiation of newborn feeding. Indian Journal of pediatrics (1988); 55(6): 905-11.

10. Mohite, RV., Kakade, SV. Knowledge of breastfeeding among primigravida mothers. Bangladesh Journal of Medical Science (2012); 11(4):312-316

How to cite this article: Devi YR, Randhawa RK, Chaudhary P. Knowledge and practice regarding breastfeeding among primipara mothers of Obstetrics ward, Birganj, Nepal. Int $J$ Health Sci Res. 2022; 12(1): 57-60. DOI: https://doi.org/10.52403/ijhsr.20220108 